\title{
Rancang Bangun Aplikasi Warta Jemaat Berbasis SMS Gateway
}

\author{
Kemur Yosua Marco ${ }^{1}$ ), Arie S. M. Lumenta ${ }^{2}$ ), Yaulie D. Y.Rindengan ${ }^{3}$ ) \\ Program Studi Teknik Informatika, Fakultas Teknik, Universitas Sam Ratulangi Manado \\ 110216070@student.unsrat.ac.id, al@unsrat.ac.id, rindengan@unsrat.ac.id
}

\begin{abstract}
Warta Jemaat merupakan media informasi dan pembinaan Gereja, khususnya Gereja Masehi Injili di Minahasa (GMIM). Warta jemaat berisikan informasi seperti jadwal Ibadah, kegiatan jemaat seperti penggalangan dana ataupun pelatihan-pelatihan yang dapat membentuk kreatifitas dan kualitas iman jemaat GMIM, laporan keuangan Gereja dan juga ucapan-ucapan baik yang berhari ulang tahun maupun yang sedang berduka. Seluruh informasi itu di satukan dan di cetak ke media kertas yang hasilnya berbentuk seperti surat kabar yang di bagikan setiap akhir pekan atau tepatnya setiap hari minggu pada saat hari beribadah. Dilain sisi, akan menjadi tidak efisien ketika sering adanya perubahan informasi seperti jadwal Ibadah dan kegiatan jemaat. Biaya juga menjadi hal yang perlu dipertimbangkan terutama bagi Gereja dengan jumlah jemaat yang banyak. Melihat dari semua itu, salah satu teknologi yang sudah di kenal oleh seluruh kalangan masyarakat adalah SMS. Menggunakan Rapid Aplication Development (RAD) sebagai metode perancangan aplikasi dan menggunakan GAMMU sebagai module SMS Gateway, penyebaran informasi Warta Jemaat diharapkan dapat menjadi lebih praktis, hemat biaya cetak, cepat dan efisien.
\end{abstract}

Kata Kunci - GAMMU, RAD, Sistem Informasi, SMS Gateway, Warta Jemaat.

\section{I .PENDAHULUAN}

Kegiatan Ibadah merupakan hal penting bagi setiap orang beragama untuk menyatakan bakti yang didasari ketaatan kepada Sang Pencinta. Seperti jemaat GMIM Paulus Titiwungen Wenang Mahakeret (TWM) yang melaksanakan ibadah, Dalam pelaksanaan ibadah, informasi menjadi bagian penting untuk terlaksannya ibadah, tidak hanya ibadah, tatapi juga seluruh kegiatan program Gereja. Sarana penyebaran informasi Gereja yaitu Warta Jemaat, Warta Jemaat Memiliki seluruh informasi Ibadah, keuangan, dan kegiatan Gereja. Warta Jemaat juga merupakan media informasi yang berupa surat kabar yang di cetak dan di perbanyak kemudian di bagikan setiap minggunya. Seringnya terjadi perubahan jadwal ibadah dan kegiatan Gereja, penyebaran informasi melalui media cetak seperti Warta Jemaat menjadi kurang efektif.. Tidak sedikit orang yang sangat bergantung atau ketergantungan pada Handphone (Nomophobia). Salah satu kehebatan teknologi yang mudah di akses perangkat handphone untuk menjembatani Informasi dengan masyarakat secara realtime dan juga sudah dikenal seluruh kalangan masyarakat adalah SMS Gateway.

\section{A. Aplikasi}

Aplikasi adalah suatu unit prangkat lunak yang dibuat untuk melayani kebutuhan akan beberapa aktivitas seperti system perniagaan, pelayanan masyarakat, periklanan, atau semua proses yang dilakukan manusia.

\section{B. SMS Gateway}

Menurut Daud Edison Tarigan (2012) SMS Gateway merupakan pintu gerbang bagi penyebaran informasi dengan menggunakan SMS. Anda dapat menyebarkan pesan kebanyak nomor secara otomatis dan cepat dan langsung terhubung dengan database nomor-nomor ponsel saja, tanpa harus mengetik ratusan nomor dan pesan di ponsel anda, karena semua nomor akan diambil secara otomatis dari database tersebut. selain itu, dengan adanya SMS Gateway, kita dapat mengolah pesan-pesan yang ingin dikirim, dengan menggunakan program tambahan yang dapat dibuat sendiri, pengiriman pesan dapat lebih fleksibel dalam mengirim berita, karena biasanya pesan yang dikirim berbeda-beda untuk masing-masing penerimanya.

\section{GAMMU}

GAMMU merupakan Software SMS Gateway yang cukup bagus dan terkenal. Selain mudah penggunaannya, perangkat modem GSM yang Support cukup banyak mulai dari Nokia, Siemens dan Sony Ericsson. Selain itu perangkat lain yang lebih cocok untuk dijadikan SMS Gateway dengan Software GAMMU seperti modem GSM Itegno. GAMMU bahkan sudah menyediakan Service Online untuk proses update data SMS ke database. database yang di Support GAMMU adalah MySQL. Ada beberapa pihak yang menginginkan program SMS Gateway nya menggunakan database yang lain seperti SQL Server, Oracle. Menggunkan sediki program tambahan kita bisa membuat Service atau program yang memanfaatkan GAMMU dan SQL server sebagai database nya.

\section{RAD (Rapid Application Development)}

Rapid Application Development (RAD) adalah strategi siklus hidup yang ditujukan untuk menyediakan pengembangan yang jauh lebih cepat dan mendapatkan hasil dengan kualitas yang lebih baik dibandingkan dengan hasil yang dicapai melalui siklus tradisional (McLeod, 2002). RAD merupakan gabungan dari bermacam-macam teknik terstruktur dengan teknik prototyping dan teknik pengembangan joint application untuk mempercepat pengembangan sistem/aplikasi (Bentley, 2004). Dari definisi-definisi konsep RAD ini, dapat dilihat bahwa 
pengembangan aplikasi dengan menggunakan metode RAD ini dapat dilakukan dalam waktu yang relatif lebih cepat.

\section{E. $P H P$}

PHP merupakan singkatan dari PHP Hypertext Preprocessor. PHP merupakan bahasa pemrograman skrip yang diletakkan dalam server yang biasa digunakan untuk membuat aplikasi web yang bersifat dinamis. Maksud web dinamis adalah dapat membentuk suatu tampilan web berdasarkan permintaan terkini, dapat dilakukan dengan menampilkan isi database ke halaman web. PHP juga digunakan secara command line, yaitu skrip PHP dapat dijalankan tanpa melibatkan web server maupun browser (Kadir, 2008:51)

\section{METODOLOGI PENELITIAN}

\section{A. Kerangka Berpikir}

Kerangka berpikir berikut merupakan serangkaian bagan-bagan yang menggambarkan alur dari proses penelitian dalam pembuatan aplikasi Warta Jemaat berbasis SMS

\section{B. Jenis dan Sumber Data}

1) Data Premiere

Data yang diperoleh langsung dari sumbernya, diamati dan dicatat pertama kalinya dalam penelitian. Data diperoleh langsung dari lokasi penelitian yaitu di Gereja GMIM Paulus TWM. Pengambilan data dilakukan melalui observasi lapangan.

2) Data Sekunder

Data sekunder ini dicari di luar dari lembaga/instansi, dan dari masyarakat setempat, artikel-artikel, dan sebagainya yang dapat menunjang perlengkapan dari penelitian

\section{Pengumpulan Data}

\section{1) Wawancara}

Metode pengumpulan data yang dilakukan dengan wawancara yaitu dengan mengajukan beberapa pertanyaan-pertanyaan yang telah disusun sedemikian rupa.

\section{2) Observasi}

Metode pengumpulan data yang dilakukan dengan cara langsung terjun ke lokasi tujuan. Dengan melakukan pencatatan langsung secara sistematis terhadap suatu objek.

3) Studi Pustaka

Metode pengumpulan data dengan mencari dan mengumpulkan beberapa referensi paper ilmiah dan bukubuku literature yang berhubungan dengan masalah yang dijadikan acuan penelitian.

\section{Metodologi Perancangan Sistem}

Metodologi Rapid Application Development adalah metodologi yang akan digunakan dalam membangun Aplikasi Warta Jemaat Berbasis SMS Gateway
1) Fase Analisis Persyaratan

Tujuan fase ini untuk mengidentifikasi dan menganalisa kebutuhan yang lebih detail dari system yang akan dibangun seperti layanan, batasan, dan objektifitas dari system dari pengumpulan data yang akan dilakukan terhadap stakeholders.

\section{2) Fase Analisis Modeling}

Tujuan dari fase analisis modeling adalah menganalisis semua kegiatan dalam arsitektur sistem secara keseluruhan dengan melibatkan identifikasi dan deskripsi abstraksi sistem perangkat lunak yang mendasar dan hubungan-hubungannya.

\section{3) Fase Desain Modeling}

Tujuan dari fase desain modeling yaitu melakukan perancangan system berdasarkan analisis yang telah dilakukan sebelumnya. Tahap analisis desain mengalami perulangan hingga di peroleh rancangan system yang benar-benar memenuhi kebutuhan. Tujuan lainnya adalah memberi spesifikasi yang jelas dan lengkap kepada programmer dan teknisi

\section{4) Fase Konstruksi}

Tujuan dari fase konstruksi adalah untuk menunjukkan hardwere dan softwere yang digunakan serta batasan dalam implementasi, serta menguji performasi prototype perangkat lunak yang telah dibangun agar dapat diketahui apakah prototype tersebut telah sesuai dengan spesifikasi analisis dan perancangan yang telah di identifikasi sebelumnya.

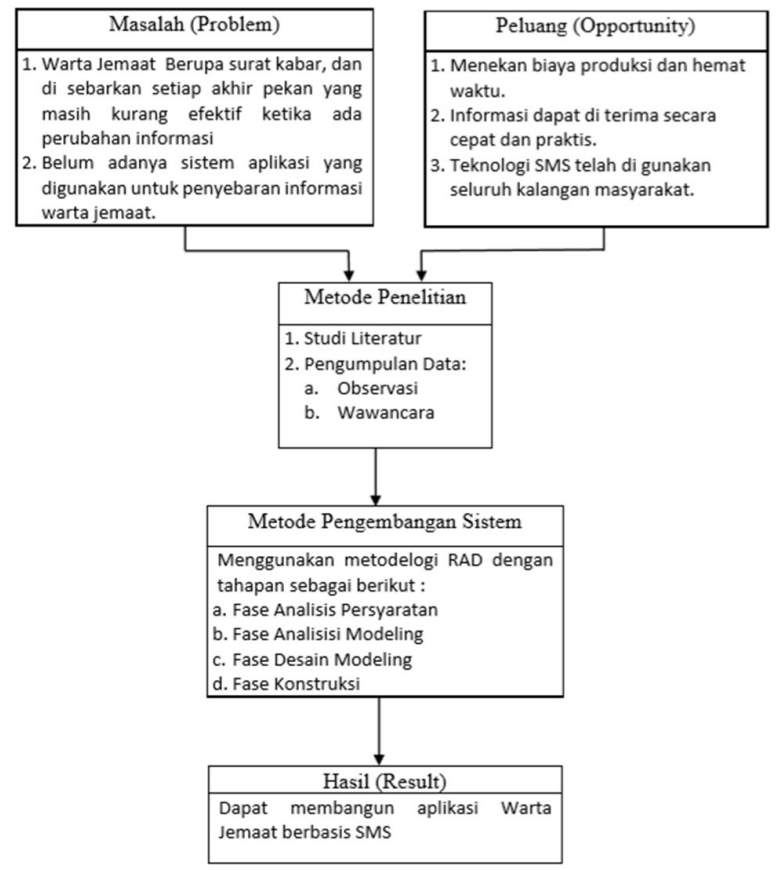

Gambar 2.1 


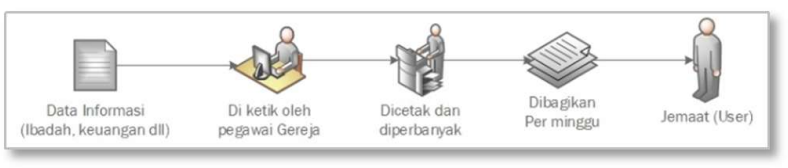

Gambar 2.2 Proses Bisnis Sistem Lama

TABEL 2.1 Penjelasan Proses Bisnis Sistem Lama

\begin{tabular}{l|l|l|l}
\hline No & Actor & Aktivitas & keterangan \\
\hline & & $\begin{array}{l}\text { Menerima data berupa } \\
\text { informasi Ibadah, } \\
\text { kegiatan, keuangan } \\
\text { dan sebagainya, yang } \\
\text { kemudian disusun dan } \\
\text { dicetak menjadi surat } \\
\text { kabar yang dinamakan } \\
\text { Warta Jemaat. }\end{array}$ & - \\
& Gegawai & $\begin{array}{l}\text { Membagikan Warta } \\
\text { Jemaat pada saat } \\
\text { Ibadah Gereja Umum } \\
\text { setiap minggu. }\end{array}$ & - \\
\hline 2. & $\begin{array}{l}\text { Penerima } \\
\text { Tamu }\end{array}$ & \multicolumn{2}{l}{} \\
\hline
\end{tabular}

Gambar 2.3

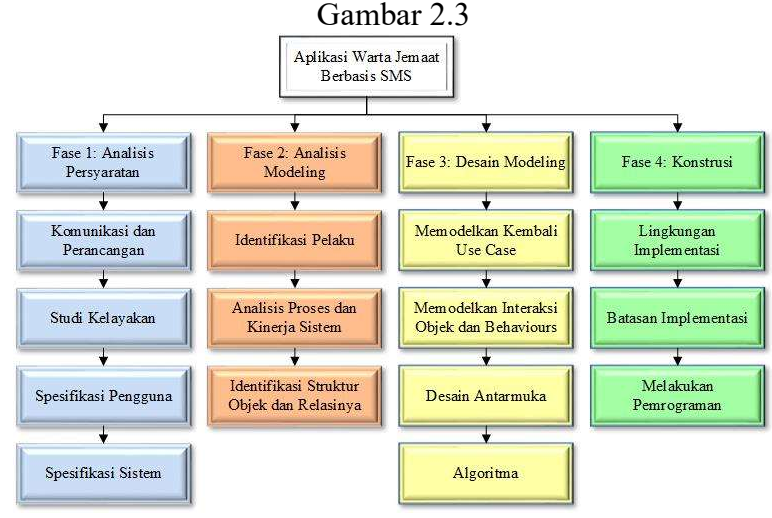

Gambar 2.3 RAD

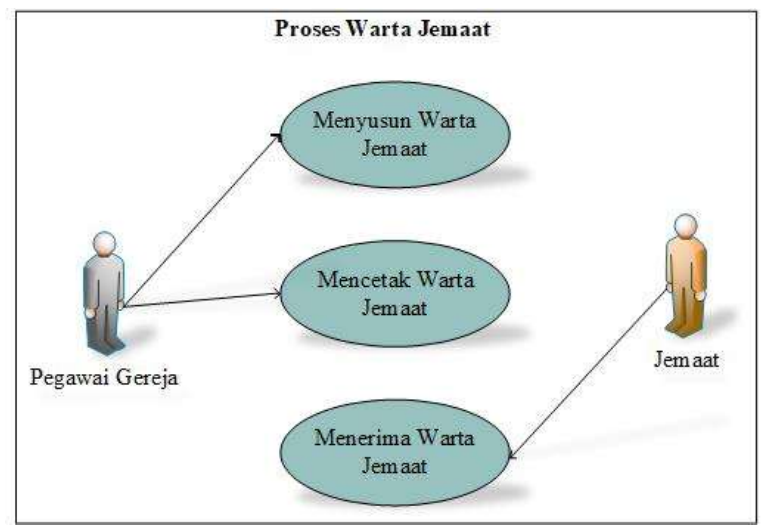

2.4 Use Case Diagram Sistem Lama

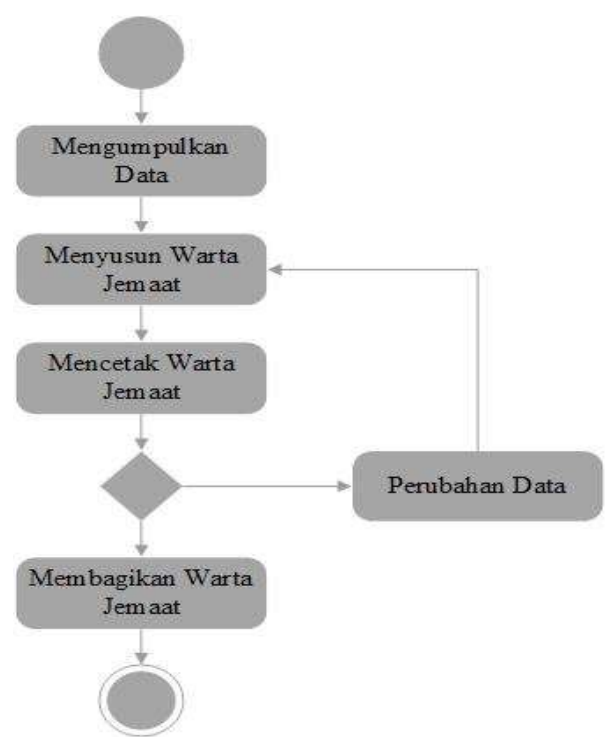

Gambar 2.5 Activity Diagram Sistem Lama

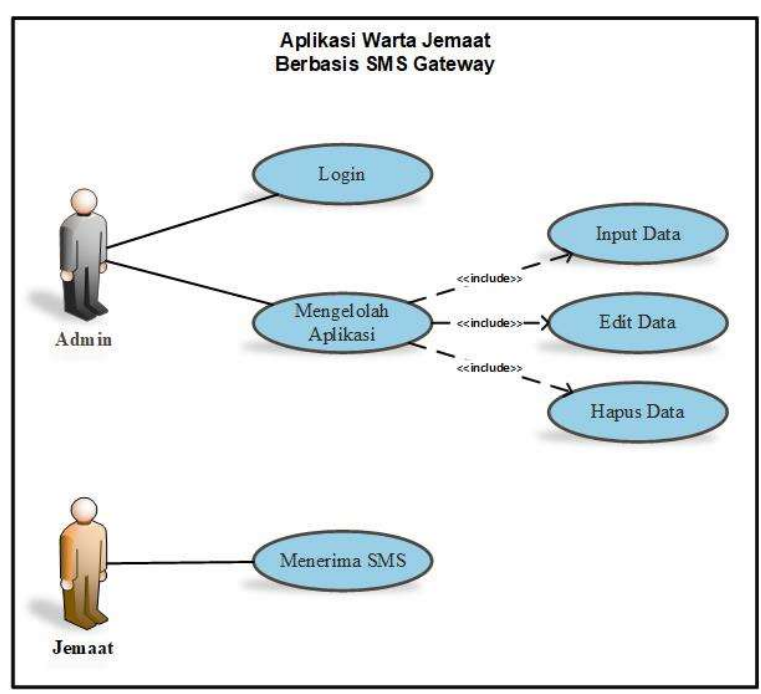

Use Case Diagram Aplikasi

TABEL 2.2 Penjelasan Uscase Diagram Aplikasi

\begin{tabular}{c|l|l}
\hline No. & $\begin{array}{l}\text { Nama Use } \\
\text { Case }\end{array}$ & Deskripsi \\
\hline 1. & Login & $\begin{array}{l}\text { Admin melakukan login untuk } \\
\text { memasuki aplikasi }\end{array}$ \\
\hline 2. & $\begin{array}{l}\text { Mengelolah } \\
\text { aplikasi }\end{array}$ & $\begin{array}{l}\text { Admin mengelolah aplikasi yang ada } \\
\text { dengan melakukan input data, edit data } \\
\text { dan hapus data }\end{array}$ \\
\hline 3. & $\begin{array}{l}\text { Menerima } \\
\text { SMS }\end{array}$ & $\begin{array}{l}\text { User menerima informasi Gereja berupa } \\
\text { SMS }\end{array}$ \\
\hline
\end{tabular}




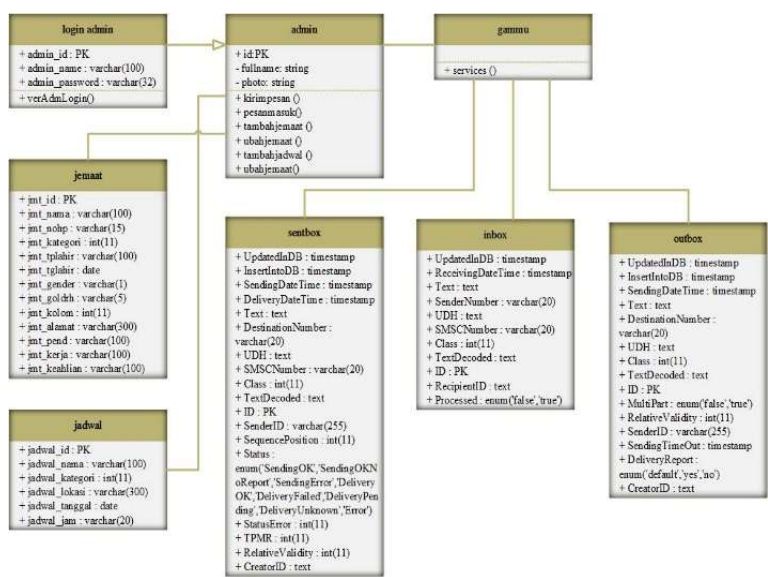

Gambar 2.5 Class Diagram Aplikasi

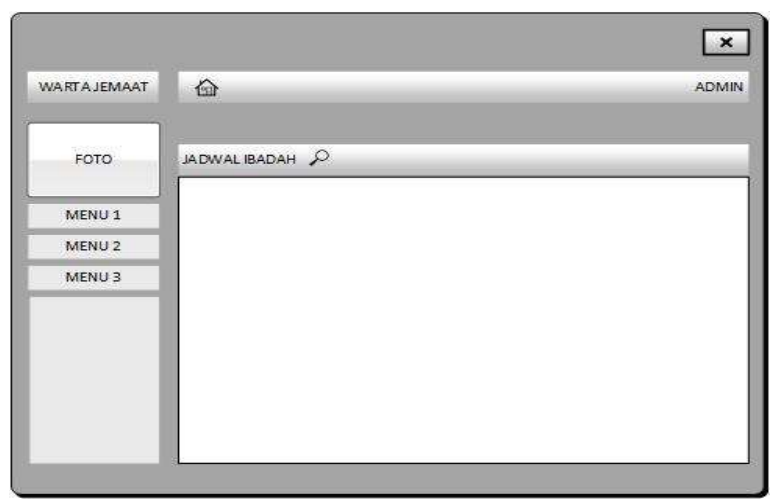

Gambar 2.6 Story Board Aplikasi

\section{HASIL DAN PEMBAHASAN}

\section{A. Implementasi Antarmuka}

Tampilan halaman admin aplikasi Warta Jemaat berbasis SMS yang telah dibuat. Terdapat menu Jadwal, Data Petugas, Data Jemaat, Seperti bisa dilihat pada gambar dibawah ini. Pada pembuatan Aplikasi menggunakan framework Codeigniter yang membuat pemrogramam $P H P$ menjadi lebih mudah, dimana framework ini memiliki pattern MVC (Model, View, Controler) sehingga struktur kode yang dihasilkan menjadi lebih terstruktur dan memiliki standar yang jelas.

\section{1) Tampilan Login Admin}

Tampilan awal aplikasi warta berbasis SMS berisi userid dan password yang hanya diketahui oleh admin. Enskripsi yang dipakai untuk password pada aplikasi ini yaitu MD5. MD5 telah dimanfaatkan secara bermacammacam pada aplikasi keamanan, dan MD5 juga umum digunakan untuk melakukan pengujian integritas sebuah berkas.

\section{2) Tampilan Halaman Login}

Pembuatan username dan password dilakukan dengan menggunakan bahasa pemrograman PHP yang telah terkoneksi dengan sistem pada aplikasi ini. Jadi, untuk membuka dan menjalankan aplikasi ini harus memasukkan username dan password.
3) Tampilan Dasboard

Tampilan dashbord adalah halaman utama pada aplikasi ini, semua button untuk mengakses informasi tersedia di halaman ini. Seperti data petugas, jadwal Ibadah, data jemaat, dan pesan. Seperti pada gambar dibawah ini.

4) Menu Jadwal Ibadah Pada halaman jadwal merupkan halaman untul menambah jadwal dan kegiatan Gereja, terdapan tombol pesan berfungsi untuk mengirim pesan, tombol edit jadwal, tambah jadwal dan tombol hapus. Informasi Ibadah pun dapat diinput dengan lengkap, dari nama, kegiatan sampai waktu dan tempat, seperti pada gambar dibawah ini.

\section{5) Tampilan Menu Tambah Jadwal}

Pada menu ini, admin bisa menambahkan jadwal Ibadah dan kegiatan Gereja, admin diharuskan mengisi format yang disediakan, seperti nama kegiatan, agar kegiatan yang akan di kirim menjadi lebih jelas dan mudah di cari, ketika mengetikan nama sebuah kegiatan di kolom pencarian. jenis kegiatan di buatkan supaya kegiatan atau jadwal Ibadah menjadi mudah di kelompokan. Tempat atau lokasi kegiatan, merupakan tempat dilakasanakannya Ibadah atau pun kegiatan Gereja.Terakhir Tanggal dan Jam Kegiatan, dibuat untuk bukan hanya melengkapi tetapi juga menjadi bagian yang nantinya ketika saat pengiriman SMS aplikasi akan menyertakan Jam dan Tanggal sesuai format yang disisi, juga dapat menentukan kapan sistem akan mengirimkan SMS. Berikur seperti pada gambar dibawah ini.

\section{6) Tombol Kirim Pesan}

Pada gambar diatas, kita bisa melihat tombol kirim pesan, berfungsi untuk mengirim jadwal dan kegiatan Gereja yang telah dibuat, terdapat juga tombol tambah petugas yang merupakan satu bagian dari warta jemaat. Fungsi dari kedua pengiriman pesan tersebut yaitu pada Tombol kirim pesan, pesan akan dikirim sesuai kategori, misalkan ketika pada jadwal dibuat kategori umum, maka pesan akan di kirimkan keseluruh nomor yang ada pada database sedangkan untuk tombol tambah petugas berfungsi untuk mengirim SMS sebagai pengingat.

\section{7) Tombol Edit Jadwal}

Seperti yang sudah dijeaskan diatas, admin bisa megedit jadwal yang sudah tersedia bila ada perubahan mendadak atau ada kesalahan. Pada gambar dibawah ini, menampikan proses untuk mengedit jawal.

\section{8) Tampilan Tambah Data Petugas}

Pada tahap ini, admin bisa menambahkan data petugas, admin diharuskan mengisi dua form yaitu peran dan petugas, dengan mengklik submit maka secara otomatis data akan langsung masuk ke database, seperti pada gambar dibawah ini.

\section{9) Menu data petugas}

Pada halaman ini, kita bisa melihat data petugas. Seperti nama, nomor handphone, kategori atau tugas sekaligus tersedia menu tambah data baru jika masih ada yang kurang. 
10) Ubadh Data Petugas

Admin juga bisa mengubah data petugas jika ada kesalahan saat menginput data petugas, untuk mengubah data petugas, bisa dilihat pada gambar dibawah ini.

11) Menu Data Jemaat

Pada menu ini, admin dapat menambahkan data jemaat sekaligus dapat melihat data jemaat. Tersedia pula pilihan untuk mengubah dan menghapus bila ada kesalahan dalam proses input data. Seperti pada gambar diatas.

\section{2) Tombol Tambah Data Jemaat}

Menu ini adalah untuk menambahkan data jemaat jika ada yang perlu ditambahkan, untuk menambahkan data jemaat, admin harus memasukkan nama lengkap, kategori, nomor handphone, tempat lahir, golongan darah, kolom, alamat, pendidikan terakhir, pekerjaan dan keahlian, format ini sesuai dengan data sensus Gereja. Beberapa format pada aplikasi ini tidak digunakan dalam pengoprasian dan pengiriman SMS, tetapi sudah dibuatkan untuk kedepan pengembangan aplikasi ini. Seperti Golongan darah yang dapat dengan mudah dalam pencarian data jemaat sehinggah juga ketika ada pengumuman berkaitan dengan golongan darah, menjadi lebih cepat untuk mengkategorikannya dan juga seperti data keahlian, biasanya pada GMIM mempunyai lombalomba kreatifitas berupa paduan suara, band, dan sebagainya, format ini dapat berfungsi untuk mengkategorikan sekaligus mengirim SMS sesuai dengan keahlian masing-masing sesuai dengan data yang di isi pada data jemaat.

\section{3) Tombol Edit Data Jemaat}

Jika terjadi kesalahan saat mengisi data jemaat, admin juga bisa mengedit data jemaat, admin diharuskan juga untuk mengisi form seperti saat memasukkan data jemaat pertama kali, bedanya, data yang di masukkan akan tersimpan di database sedangkan saat di edit, database yang sudah ada akan dirubah isi informasinya, seperti pada gambar dibawah ini.

\section{4) Mengirim SMs}

Aplikasi Warta Jemaat berbasis SMS akan mengirimkan SMS sesuai informasi yang di input oleh admin, proses pengiriman akan di lakukan GAMMU pada saat admin menekan tombol kirim dan juga bisa dengan mengatur jadwal pengiriman sesuai tanggal yang di tentukan, berikut gambar yang menunjukan hasil pengiriman SMS dari Aplikasi Warta Jemaat dimana dapat dilihat aplikasi berhasil mengirimkan informasi kegiatan ibadah pemuda yang lokasi dan jamnya sesuai yagn telah di input admin. Selain mengirimkan jadwal ibadah Aplikasi Warta Jemaat Berbasis SMS Gateway ini dapat mengirimkan pesan untuk petugas yang bertugas dalam ibadah tersebut sebagai pengingat. Beirkut pada Gambar 4.15 dapat dilihat hasil pengiriman SMS Aplikasi Warta Jemeat untuk petugas Ibadah.

\section{PENUTUP}

\section{A. Kesimpulan}

1) Dengan menggunakan metode perancangan aplikasi Rapid Application Development (RAD) penulis menemukan perancangan menjadi lebih cepat namun tetap akurat dimana ke empat fase yang ada pada RAD sendiri dapat menghasilkan Dokumen yang akurat untuk menunjang terbetuknya Aplikasi Warta Jemaat Berbasis SMS Gateway ini.

2) Penulis dapat memahami cara kerja dari SMS Gateway, dimana GAMMU sebagai module menjadi bagian penting untuk menghubungkan database aplikasi dan modem $S M S D$. cara kerja GAMMU yang sederhana juga dapat penulis pahami seperti GAMMU hanya memproses seluruh SMS yang ada pada database MySQL tabel Outbox yang dibuat GAMMU sendiri, yang kemudian setelah di kirimkan melalui modem $S M S D$, pesan yang telah di proses di pindakan ke database table Sentitem.

3) Warta Jemaat yang menggunakan sistem lama memiliki sejumlah kekurangan dan setelah menggunakan sistem dengan SMS Gateway, penulis melihat beberapa keunggulan salah satunya yaitu efisiensi waktu dimana pesan dari Informasi Gereja dapat langsung di terima tanpa harus menunggu satiap minggu dan juga ketika perubahan mendadak dari Informasi Gereja.

B. Saran

1) Sistem ini dapat dikembangkan lagi dengan menambahkan fitur-fitur yang dapat mendukung penyebaran informasi Gereja menjadi lebih baik lagi.

2) Melihat dari pengujian aplikasi, admin sebagai pengelolah Aplikasi, kiranya dapat lebih memperhatikan pengiriman SMS agar tidak terjadi kegagalan di akibatkan human error, seperti tidak menjalakan service dari GAMMU.

\section{DAFTAR PUSTAKA}

Abdul Kadir. 2003. Pengenalan Sistem Informasi. Andi, Yogyakarta.

Abdul Kadir. 2008. Tuntunan Praktis Belajar Database Menggunakan $M y S Q L$. C.V Andi Offset. Yogyakarta.

Anggi Bingar Kusuma, Bambang Eka Purnama. 2015. Sistem Notifikasi Keluhan Pelanggan Berbasis SMS Gateway Pada Perseroan Terbatas (PT) Telkom Unit Pelayanan Ngadirojo. IJNSIndonesian Journal on Networking and Security - Vol 4, No. 3

Canggih Ajika Pamungkas. 2015. Pemanfaatan Codeigniter Framework Dalam Membangun SMS Gateway Berbasis GAMMU. Jurnal Informatika Politeknik Indonusa Surakarta. Vol 1. No. 1

Cheren Willsen Tiwow. 2017. Rancang Bangun Aplikasi Sekolah Berbasis SMS. E-journal Teknik Informatika, Vol 13. No 1

Christine N.R.H Tanor, Jelly S. D. A. Rompas. 2016. Buku Profil GMIM Paulus Titiwungen Wenang Mahakeret. Manado

Dimas Anggoro. 2013. Sistem Informasi Penjualan Produk Minuman Cocacola Di Amc Cabang Pacitan Berbasis SMS Gateway. IJNS - Indonesian Journal on Networking and Security.

Dittman, Whitten Bentley. 2004. Systems Analysis and Design Methods.McGraw-Hill Companies. 
Evert S. Tangkudung. 2018. Aplikasi Tata Cara Ibadah Berbasis Android. E-Journal Teknik Informatika. Vol 14. No. 1

Gorby Pitoi. 2016. Perancangan Sistem Informasi Jemaat dan Pekerja Gereja Masehi Injili di Minahasa. E-Journal Teknik Elektro dan Komputer. Vol 5. No. 5

Hengky W. Pramana. 2006. Aplikasi Inventory Berbasis Access 2003. Elex Media Komputindo. Jakarta.

Kendall, K. E., dan Kendall, J. E. 2010. Analisis dan Perancangan Sistem. Jakarta: PT Indeks.

O'Brien, James A., Marakas, George M (2006). Management Information System. McGraw-Hill Inc, New York.

Pressman, Roger S. (2002). Rekayasa Perangkat Lunak: Pendekatan Praktisi Buku 1. Andi Offset, Yogyakarta

Randi V. Palit. 2015. Rancangan Sistem Informasi Keuangan Gereja Berbasis Web Di Jemaat GMIM Bukit Moria Malalayang. EJournal Teknik Elektro dan Komputer. Vol 4. No 7.

Ribka Judita Veronica Pakasi. 2015. Aplikasi Monitoring KTP Kota Manado Menggunakan SMS Gateway. Teknik Elektro Fakultas Teknik Universitas Sam Ratulangi. Manado

Tarigan, Daud Edison. 2012. Membangun SMS Gateway Berbasis Web dengan CodeIgneter. Lokomedia Yogyakarta

Yaulie Deo. Y. Rindengan. 2016. Rancang Bangun Aplikasi Fasilitas Umum Berbasis Web Services. E-journal Teknik Informatika. Teknik Informatika Universitas Sam Ratulangi Manado, Indonesia.

Yoshiko Tanaka Lumintang. 2015. Rancang Bangun WEB Service Sistem Informasi Terintegrasi Gereja Masehi Injili di Minahasa (Studi Kasus : Gereja GMIM Getsemani Lansot Tomohon). E-journal Teknik Informatika. Vol 5. No. 1

Yosua Y. Y. Syahrir. 2018. Rancang Bangun Aplikasi Cross Protocol Email dan SMS. E-journal Teknik Informatika. Vol 13, No. 1

Yudi Wiharto. 2015. Sestem Informasi Akademik Berbasis SMS Gateway. Politeknik PalComTech Palembang. Vol 1, No.1

\section{SEKILAS TENTANG PENULIS}

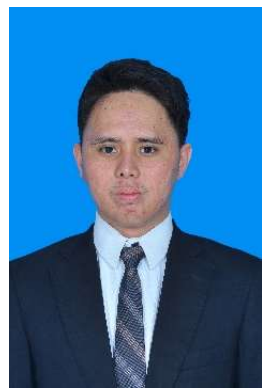

Sekilas dari penulis dengan nama lengkap Kemur Yosua Marco, lahir di Manado 07 Januari 1994, Provinsi Sulawesi Utara. Anakkedua dari tiga bersaudara. Dengan pendidikan Sekolah Dasar GMIM 1 Manado. Kemudian Melanjutkan ke Sekolah Menengah Pertama Negeri SMP Katolik St. Dominiko Savio Manado. Kemudian melanjutkan ke Sekolah Menengah SMK Negeri 1 Manado. Setelah lulus tahun 2011 melanjutkan ke Perguruan Tinggi di Universitas Sam Ratulangi Manado dengan mengambil Jurusan Teknik Informatika. Pada tahun 2018 bulan maret, penulis membuat Skripsi demi memenuhi syarat Sarjana (S1) dengan penelitian berjudul Rancang Bangun Aplikasi Warta Jemaat Berbasis SMS Gateway yang di bimbing oleh dua dosen pembimbing yaitu Arie S. M. Lumenta, ST., MT dan Yaulie D. Y. Rindengan ST., Msc., MM sehingga pada tanggal 20 September 2018 penulis resmi lulus di Teknik Informatika Universitas Sam Ratulangi Manado dan menyandang gelar Sarjana Komputer dengan predikat Sangat Memuaskan. 